\title{
Safety of Pedicle Screws in Adolescent Idiopathic Scoliosis Surgery
}

\author{
Chris Yin Wei Chan, Mun Keong Kwan \\ Department of Orthopaedic Surgery, National Orthopaedic Centre of Excellence for Research and Learning (NOCERAL), Faculty of Medicine, \\ University of Malaya, Kuala Lumpur, Malaysia
}

To review existing publications on the safety of pedicle screw insertions in adolescent idiopathic scoliosis (AIS). Despite having increased risk for neurological and visceral injuries, the use of pedicle screws have led to increased correction rates in scoliosis surgery. A review was performed on topics pertinent to pedicle screw insertion in AIS, which included pedicle morphometry in AIS, structures at risk during pedicle screw insertion, and accuracy and safety of various pedicle screw insertion techniques. The importance of computer navigation and future research regarding pedicle screw placement in AIS were also briefly reviewed. Many authors have reported abnormal pedicle anatomy in AIS. Injury to the neural structures was highest over the apical region, whereas aortic injury was the highest at T5 and T10. In the proximal thoracic spine, the esophagus could be injured even with screws as short as 25 $\mathrm{mm}$. Overall pedicle perforation rates for perforations $>0$ and $>2 \mathrm{~mm}$ (assessed by computed tomography) ranged from $6.4 \%$ to $65.0 \%$ and $3.7 \%$ to $29.9 \%$, respectively. The critical pedicle perforation (>2 $\mathrm{mm}$ excluding lateral thoracic) and anterior perforation (>0 mm) rates was reported to range from $1.5 \%$ to $14.5 \%$ and $0.0 \%$ to $16.1 \%$, respectively. Pedicle perforation rates were lower with the use of computer navigation. The incidence of neurological adverse events after scoliosis surgery was $0.06 \%-1.9 \%$. Aortic injury has only been observed in case reports. According to the available literature, pedicle screw insertion in AIS is considered safe with low rates of clinical adverse events. Moreover, the use of navigation technology has been shown to reduce pedicle perforation rates.

Keywords: Safety; Perforation; Pedicle screw; Adolescent idiopathic scoliosis

\section{Introduction}

Although Boucher [1] was credited with the introduction of pedicle screws in 1959, Harrington and Tullos [2] were the first to introduce the concept of inserting the screws into the axis of the pedicle. However, it was not until the eighties that pedicle screws gained popularity after RoyCamille et al. [3] published his results. Pedicle screws offer the advantage of three-column purchase of the vertebrae with higher pull-out strength and better rotational control [4]. These biomechanical advantages have translated into higher correction rates after scoliosis surgery [5-10]. However, recent studies have shown that pedicle screw insertion in adolescent idiopathic scoliosis (AIS) has the risk for causing injury not only to the nervous system but also to the surrounding viscera, which include the aorta, azygos vein, and esophagus [11-13].

\section{Pedicle Anatomy in Scoliosis and Its Relation with the Surrounding Viscera}

A number of researchers have studied the anatomy of the

\footnotetext{
Received Feb 28, 2017; Revised Apr 18, 2017; Accepted Apr 20, 2017

Corresponding author: Mun Keong Kwan

Department of Orthopaedic Surgery, National Orthopaedic Centre of Excellence for Research and Learning (NOCERAL), Faculty of Medicine, University Malaya, 50603 Kuala Lumpur, Malaysia

Tel: +60-379492061, Fax:+60-379494642, E-mail: munkeong42@hotmail.com
} 
pedicle in normal thoracic and lumbar spines. Panjabi et al. [14] reported that the narrowest pedicle width was at the T3-T8 level wherein the average width was $6.3 \mathrm{~mm}$. Zindrick et al. [15] analyzed 2,905 pedicles and concluded that the narrowest pedicle in their series was at T5. In general, most authors agree that the narrowest pedicle width was at the T4-T6 vertebrae [14-16]. Asians have narrower pedicle width as reported in many studies, with Tan et al. [17] reporting that the Asian pedicle width was on an average $25.7 \%$ narrower [18].

Liljenqvist et al. [19] found that the endosteal pedicle width in scoliotic spines was narrower at the concavity of the middle thoracic curve. Parent et al noted similar findings. The width of concave pedicles is narrower such that the mean difference at the T8 and T4 levels was 1.37 and $1.68 \mathrm{~mm}$, respectively. The mean left pedicle width at T8 was $4.08 \mathrm{~mm}$, whereas the mean right pedicle width at T4 was $2.60 \mathrm{~mm}$ [20]. Sarwahi et al. [21] reported higher rates of abnormal pedicles in patients with AIS, most of which were in the thoracic spine (31.9\%). More abnormal pedicles were found in the concavity, within the periapical region, and on the apex of the curve [21]. Czerwein et al. [22] graded the abnormal pedicles using 42 preoperative computed tomography (CT) images and found that incidences of type $\mathrm{C}(<4 \mathrm{~mm}$ width with no cancellous channel) and type D ( $<2 \mathrm{~mm}$ with no cancellous channel) pedicles were $4.4 \%$ and $3.2 \%$, respectively. Increased rates of malpositioned screws were found in dysmorphic pedicles, with a perforation rate of $28.1 \%$ [22]. Watanabe et al. [23] also proposed a novel pedicle channel classification and noted that more abnormal pedicles were present on the concave side, particularly in the proximal thoracic spine.

Sarlak et al. [24] analyzed visceral structures at risk during pedicle screw insertion in AIS corrective surgery. They concluded that the highest risk for spinal cord injury was at the "concave" proximal thoracic spine at the T2 and T3 levels and at the "concave" mid thoracic spine at the T5T9 levels. Convex-sided screws at T4-T9 had the highest risk for pleural injury, whereas concave-sided screws at T4-T8 and convex-sided screws at T11-T12 increased the risk for aortic injury [24]. Jiang et al. [11] noted that when placed in the prone position, patients who had AIS with a single thoracic curve presented an anteromedial shift in the aorta toward the spine at the T5-T10 levels. The risk for aortic injury was the highest on the left side at T5 and T11 [11]. Liu et al. [25] analyzed 47 patients with
AIS using preoperative CT and found that the highest risk for aortic injury was at T10 followed by T4, with pedicleaorta angles of $7.45^{\circ} \pm 6.10^{\circ}$ and $8.89^{\circ} \pm 6.49^{\circ}$, respectively.

Takeshita et al. [26] evaluated the risk for aortic injury during the insertion of right side pedicle screws and noted a risk for aortic injury at the left thoracic or major curve. A 50-mm right pedicle screw placement with an error of $20^{\circ}$ directed laterally would lead to a $33 \%$ risk for aortic injury in a $21^{\circ}$ left lumbar curve. A larger apical vertebral translation, Cobb angle, and Nash-Moe grade also increased the risk for injury [26].

Takeshita et al. [27] found that the screw length that increases the risk for esophageal injury in a scoliotic spine was only 30.5 and $29.4 \mathrm{~mm}$ in the concave and convex side at the T4 level, respectively. In a recent report, Jiang et al. [12] noted a higher risk for azygous vein injury on the left thoracic vertebrae (T7-T10) during pedicle screw insertion. The risk for azygous vein injury on the left side ranged from $72 \%$ at $\mathrm{T} 10$ to $85 \%$ at $\mathrm{T} 8$. In patients without abnormalities, no risk for azygous vein injury was observed on both sides [12].

\section{Pedicle Screw Malpositioning and Neuro- logical Injury in Scoliosis}

Pedicle screw perforation rates reported in the literature vary widely from $1.2 \%$ to $65.0 \%$ (Tables 1,2 ) [28-49]. This wide variation in pedicle perforation rates was influenced by the method of assessment, which was performed using plain radiography or CT. Studies that used plain radiographic assessment had very low total perforation rates ranging from $1.2 \%$ to $3.0 \%[28,33,35,38,42]$. In one of the largest series that report on pedicle screw accuracy in spinal deformities, 4,604 thoracic pedicle screws were analyzed in 462 cases. The rate of screw malpositioning in patients with idiopathic scoliosis was $1.2 \%$ (45 cases of screw malpositioning/3,751 screws). Moreover, four patients experienced screw-related neurological deficits $(0.8 \%)$, one having transient paraparesis and three having dural tears. A total of 11 intraoperative pedicle fractures, 35 screw loosening, nine infections, and one pneumothorax not related to screw placement were identified. However, only 20 CT were available for review. The other patients were evaluated using only plain radiographs [28].

Studies that used only CT to evaluate the position of all pedicle screws had higher perforation rates ranging from $6.4 \%$ to $65 \%$ [29-32,34,36,37,39-41,43-49]. However, 
reported perforation rates based on CT varied widely as well. One of the main reasons for this variation was the difference in the use of the pedicle perforation grading system. Samdani et al. [43] and Liu et al. [44] conducted the largest series of CT pedicle screw assessment, which included 45 patients with 856 screws and 92 patients with 712 screws, respectively. Perforation rates in their series were $12.1 \%$ and $32.0 \%$, respectively. Further evaluation of data from these two articles revealed that Samdani et al. [43] only considered pedicle perforations $>2 \mathrm{~mm}$, whereas Liu et al. [44] included any perforation $>0 \mathrm{~mm}$ for data analysis. The actual perforation rate for pedicles $>2 \mathrm{~mm}$ in Liu et al's series was $15.4 \%$ [44].

Hicks et al. [50], in a systematic review of pedicle screw complications during scoliosis surgery, analyzed 4,570 screws in 1,666 patients. Only 12/21 studies specifically evaluated pedicle screw malpositioning. Moreover, only six studies involving 2,202 screws in 184 patients evaluated the screw position using CT. A temporary neurological deficit was observed only in $1 / 1,666$ patients. In studies using CT for evaluation, the rate of screw malpositioning was as high as $15.7 \%$. Furthermore, 11/1,666 patients underwent revision surgery for screw malpositioning. The authors identified nine case reports regarding vascular injury and neurological deficit with 10 and 4 cases, respectively [50].

In 2016, Sarwahi et al. [51] defined screw at risk (SAR) as a medial breach $>4 \mathrm{~mm}$ or an anterior/lateral breach with a $<1 \mathrm{~mm}$ margin from the viscera. Using their classification, a $1.06 \%$ SAR rate was obtained. However, a perpatient-based outcome analysis showed that $14.2 \%$ of the patients had SAR [51]. Despite the number of reports on pedicle screw misplacements in scoliosis, the significance of these misplacements is hard to determine given that the actual rate of neurological injuries secondary to screw misplacements might be underreported. The rate of new neurological deficits following scoliosis surgery was $0.99 \%$, whereas the incidence of spinal cord injury was $0.56 \%$. The cause of neurological deficits had not been stated in this report [52].

Samdani et al. [53] reported that $2.2 \%$ of those who used pedicle screws had an early reoperation (11/540 cases). The most common reason for early reoperation was malpositioned pedicle screws, which occurred in $1.7 \%$ of the cases (9/540). Among the nine patients, three had radiculopathy and one had transient myelopathy [53]. MacThiong et al. [54] reported on the neurological outcome and management of nine scoliosis cases with intra-canal screws. In two patients, both having motor deficit, pedicle screw misplacement was recognized intraoperatively, which prompted the removal of all screws. Moreover, two patients presented with postoperative postural headache, while five patients had an uneventful early postoperative course. One patient developed Brown-Sequard syndrome 2 years postoperatively, whereas another developed left thoracic paraesthesia 3 years postoperatively [54].

Dede et al. [55] investigated the incidence of neurological symptoms secondary to misplaced screws in AIS. They concluded that $9 / 481$ patients (1.9\%) developed symptoms, of which six had pedicle screw malpositioning and three underwent revision. Those who underwent revision had a 3-mm breach at the left $\mathrm{L} 2$, a $7-\mathrm{mm}$ medial breach at the left L2 and L3 screws, and orthostatic headache due to medially placed left T9 and T12 screws. Another three patients developed dermatomal pain because of medially placed screws at the thoracic spine, two over the concave region and one over the convex region [55].

Table 1 summarizes published reports on the accuracy of pedicle screw insertion, i.e., perforation rate, using the conventional technique without the use of navigation according to the etiology of scoliosis, screw insertion technique, screw assessment method, and the rate of perforation relative to the severity thereof. The inclusion of pedicle perforations $>0 \mathrm{~mm}$ (assessed by CT) resulted in an overall pedicle perforation rate ranging from $6.4 \%$ to $65.0 \%$. However, the rate for pedicle perforations $>2 \mathrm{~mm}$ ranged from $3.7 \%$ to $29.9 \%$. Critical pedicle perforation, defined as perforations $>2 \mathrm{~mm}$ (excluding lateral pedicle perforations in the thoracic spine due to the use of extrapedicular screws), ranged from $1.5 \%$ to $14.5 \%$, whereas the anterior perforation rate $(>0 \mathrm{~mm})$ was reported to range from $0.0 \%$ to $16.1 \%$ (Table 1 ).

Computer navigation-assisted pedicle screw fixation during AIS surgery has been shown to increase accuracy and reduce surgical time and radiation [34,44,56]. Zhang et al. [49] also showed that intraoperative navigation systems facilitate pedicle screw insertion in patients with AIS, which resulted in better efficiency and accuracy of pedicle screw placement in the apical region of the scoliotic spine than preoperative navigation. Table 2 summarizes published reports on the accuracy of pedicle screw insertion using navigation systems according to the etiology of scoliosis, navigation technique, screw assessment method, and the rate of perforation relative to the severity thereof. 


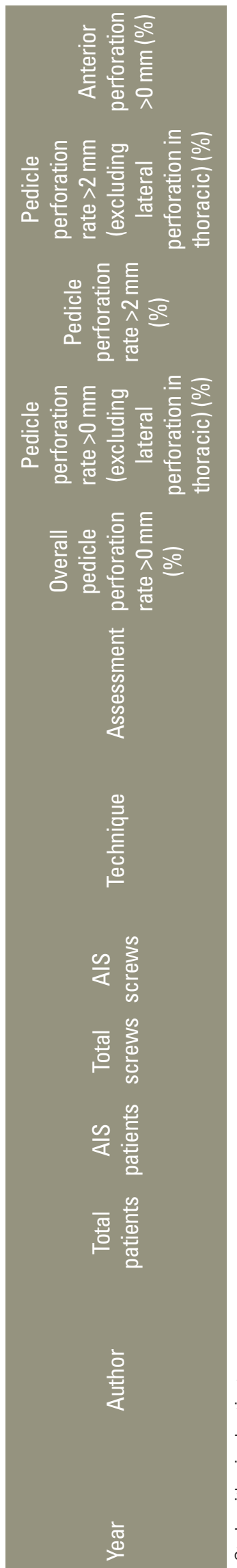

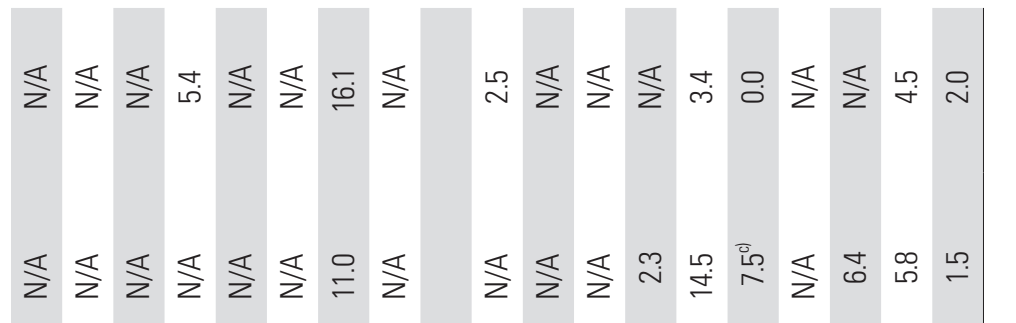

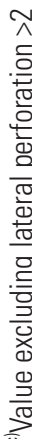

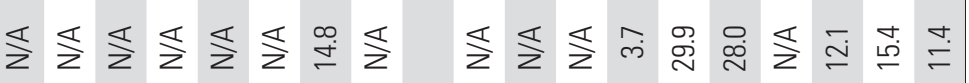

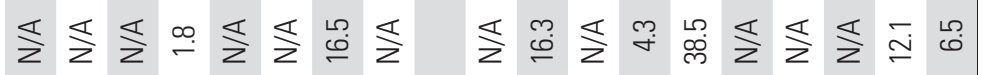

뚱

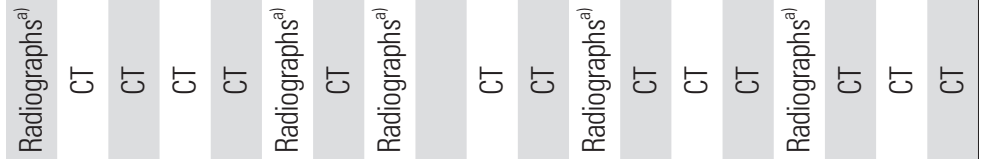

đi

$\frac{.0}{\circ}$

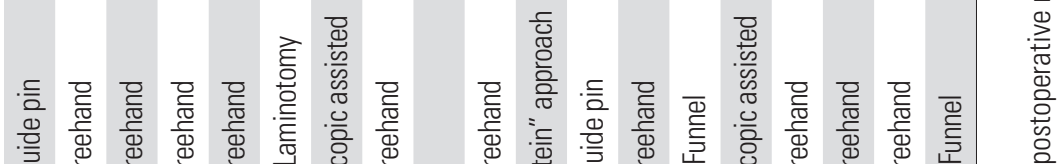

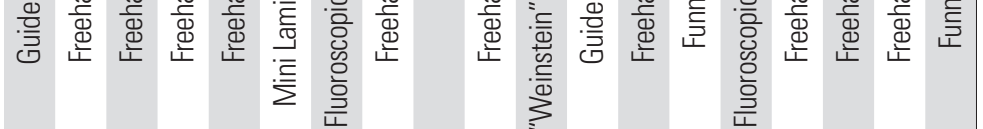

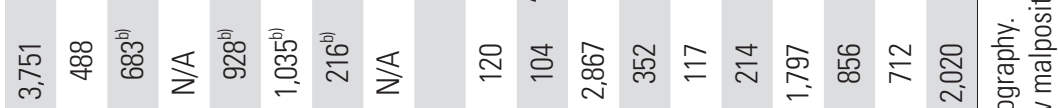

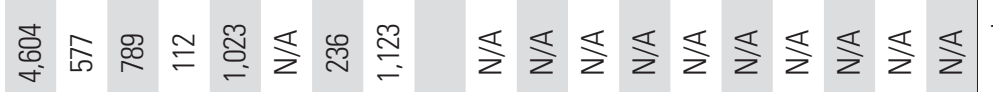

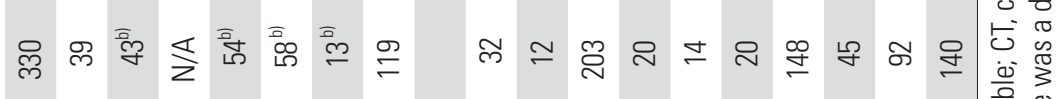

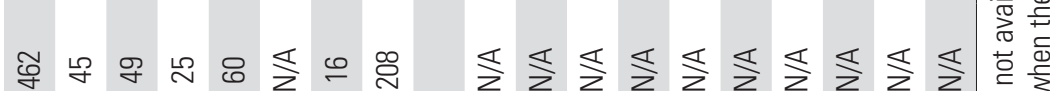

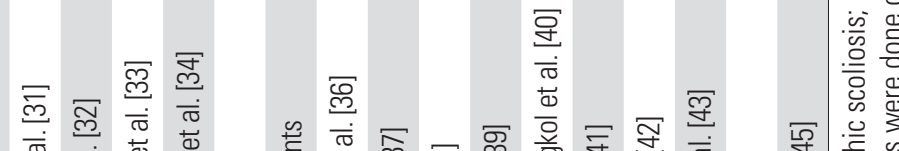

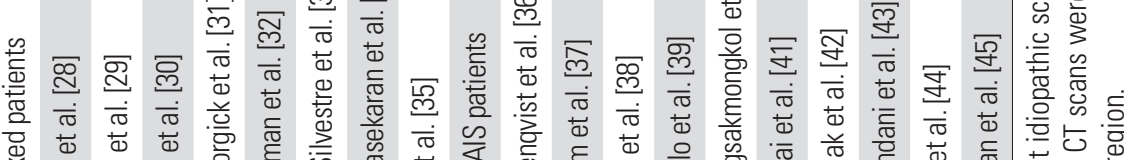
㐘

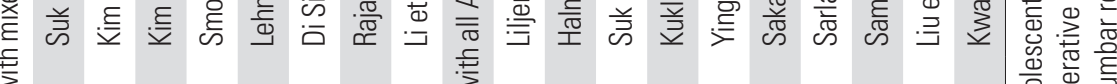

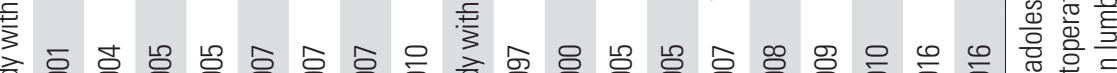

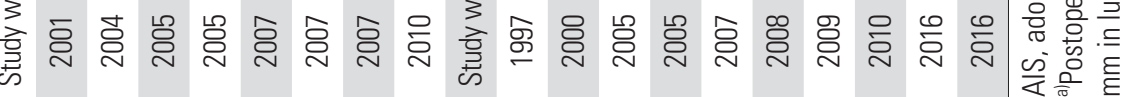




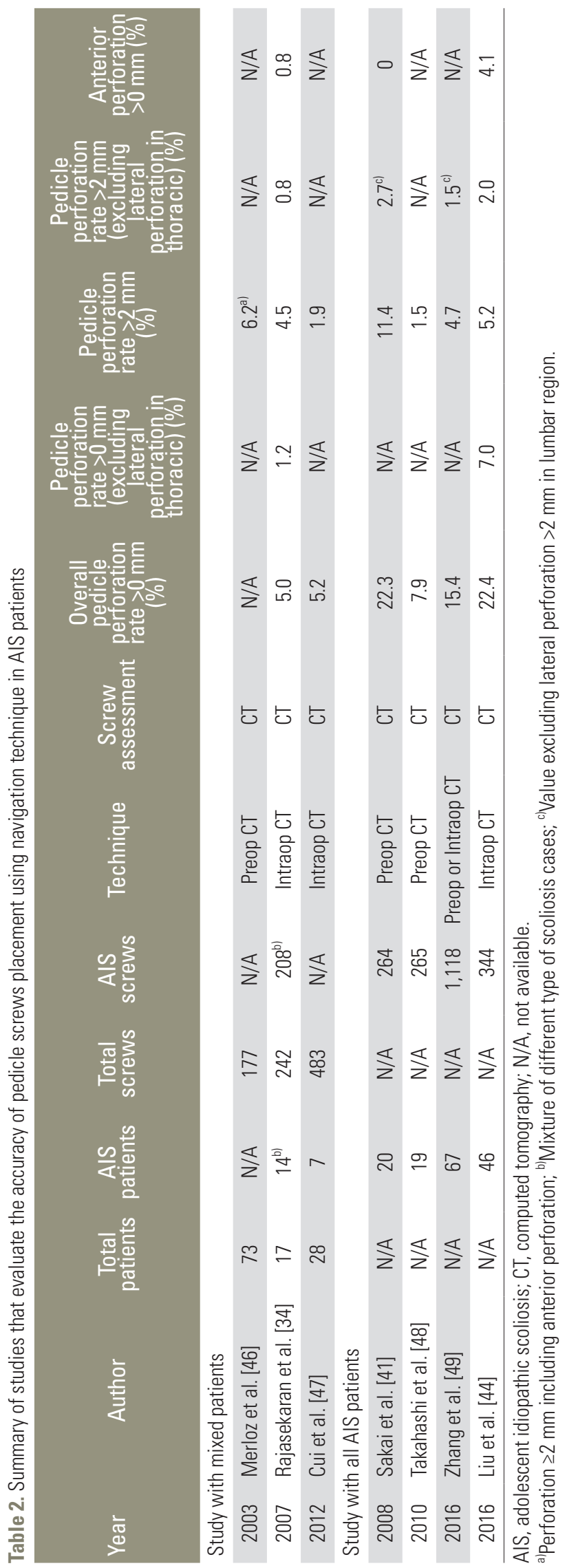

The inclusion of pedicle perforations $>0 \mathrm{~mm}$ (assessed by CT) resulted in an overall pedicle perforation rate ranging from $5.0 \%$ to $22.4 \%$. However, the rate for any pedicle perforation $>2 \mathrm{~mm}$ ranged from $1.5 \%$ to $11.4 \%$. Critical pedicle perforation, defined as perforations $>2 \mathrm{~mm}$ (excluding lateral pedicle perforation in the thoracic spine due to the use of extrapedicular screws), ranged from 1.5\% to $2.7 \%$, whereas the anterior perforation rate $(>0 \mathrm{~mm})$ was reported to range from $0.0 \%$ to $4.1 \%$ (Table 2 ).

\section{Pedicle Perforation and Pedicle Screw Insertion (Non-Navigation) Technique}

Many authors have described various pedicle screw insertion techniques for scoliosis surgery. Among the more popular techniques included are the freehand technique, fluoroscopy-assisted insertion technique, and the funnel technique $[28-30,34,40,45]$. The freehand technique was popularized by Kim et al. [29], who reported an overall pedicle perforation rate of $6.4 \%$. The fluoroscopy-assisted insertion technique was introduced by Suk et al. [28], who reported a perforation rate of only $1.2 \%$. However, in this series, majority patients were assessed using only radiography [28]. Yingsakmongkol et al. [40] reported on the use of the funnel technique and found that the overall pedicle perforation rate in their 14 patients was $65.0 \%$. In 2016, Liu et al. [44] reported on the accuracy of the freehand technique among patients with AIS (assessed using CT), revealing an overall perforation rate of $32.0 \%$. However, the exclusion of lateral thoracic perforations resulted in an overall pedicle perforation rate of $12.1 \%$ [44]. Kwan et al. [45] reported on the accuracy of the funnel technique in a large study population of 140 patients with AIS, evaluating 2,020 pedicle screw placements using CT. Although the overall pedicle screw perforation rate was $18.3 \%$, the exclusion of lateral thoracic perforations lowered the perforation rate to $6.5 \%$ [45].

\section{Aortic Injury in Scoliosis Surgery}

The actual incidence of aortic injury following pedicle screw instrumentation remains unknown. Hicks et al. [50] performed a meta-analysis on complications of pedicle screw fixation in scoliosis surgery and reported aortic abutment in $6 / 8,147$ screws with an incidence of $0.07 \%$. However, actual injuries to the aorta were rarely reported. Aortic abutment by the hardware, i.e., screw, can be as- 
sessed by postoperative CT, whereas contour deformation can be confirmed with an aortogram as described by Sucato et al. [57].

Several case reports have been published regarding non-scoliosis surgery. Watanabe et al. [58] reported a case of aortic penetration caused by a left T10 pedicle screw following posterior spinal fusion from T10 to L2 for an osteoporotic compression fracture. The patient underwent simultaneous screw removal and aortic defect repair (by a vascular surgeon) while in the right lateral decubitus position. Kakkos and Shepard [59] reported a case of spinal tuberculosis with instrumentation from T11 to L2 wherein aortic injury was caused by the left T11 pedicle screw. The patient subsequently underwent aortic repair and screw tip burring. Minor et al. [60] described the use of an endovascular technique in the management of aortic injury secondary to pedicle screw injury. The patient, a 77-year-old woman who underwent posterior spinal instrumentation for kyphoscoliosis, was noted to have a left T5 pedicle screw abutting the aorta. Aortograms confirmed that the screw had penetrated the wall of the thoracic aorta. The patient subsequently underwent simulta- neous endovascular stenting and pedicle screw removal [60]. Iyer et al. [61] advocated the use of transesophageal echocardiography for identifying leakage from the aortic injury due to pedicle screw malpositioning. Their report examined a case of aortic impingement due to a left T8 screw following T4-S1 posterior spinal fusion for degenerative scoliosis [61].

Sarlak et al. [42] analyzed screw placement accuracy in 19 patients who underwent scoliosis surgery and noted aortic abutment in 7/185 screws (3.8\%). In their series of 25 cases, Smorgick et al. [31] reported aortic abutment in 2/112 screws (1.8\%). Wagner et al. [62] described aortic abutment after direct vertebral rotation, which occurred in six patients. All screws, three of which were at T9 and one at T7, T12, and right L3, were at the apical region and within the concavity of the spine.

\section{Discussion}

\section{Our experience}

We had recently published an article on the accuracy and

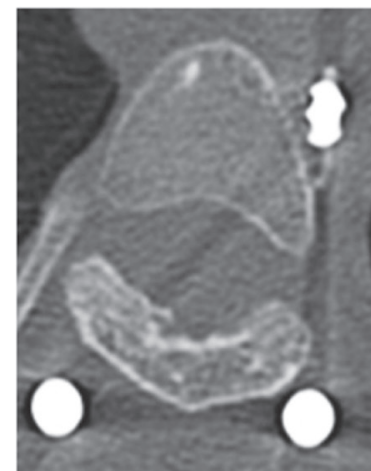

A

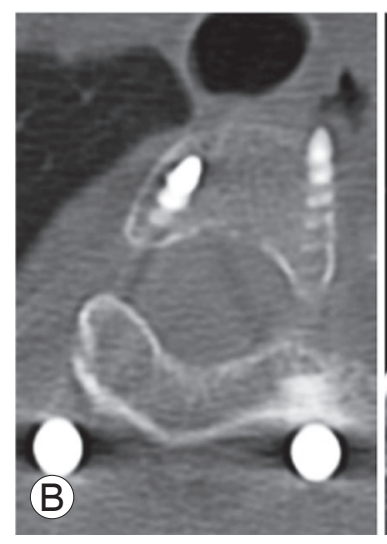

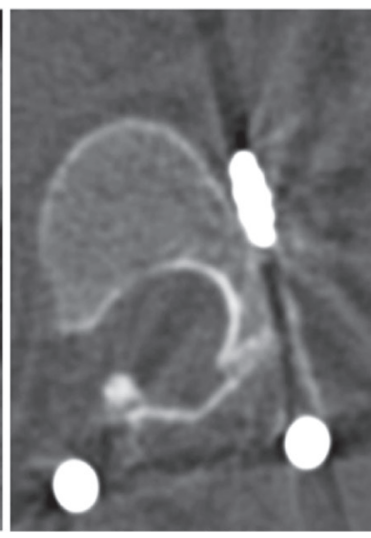
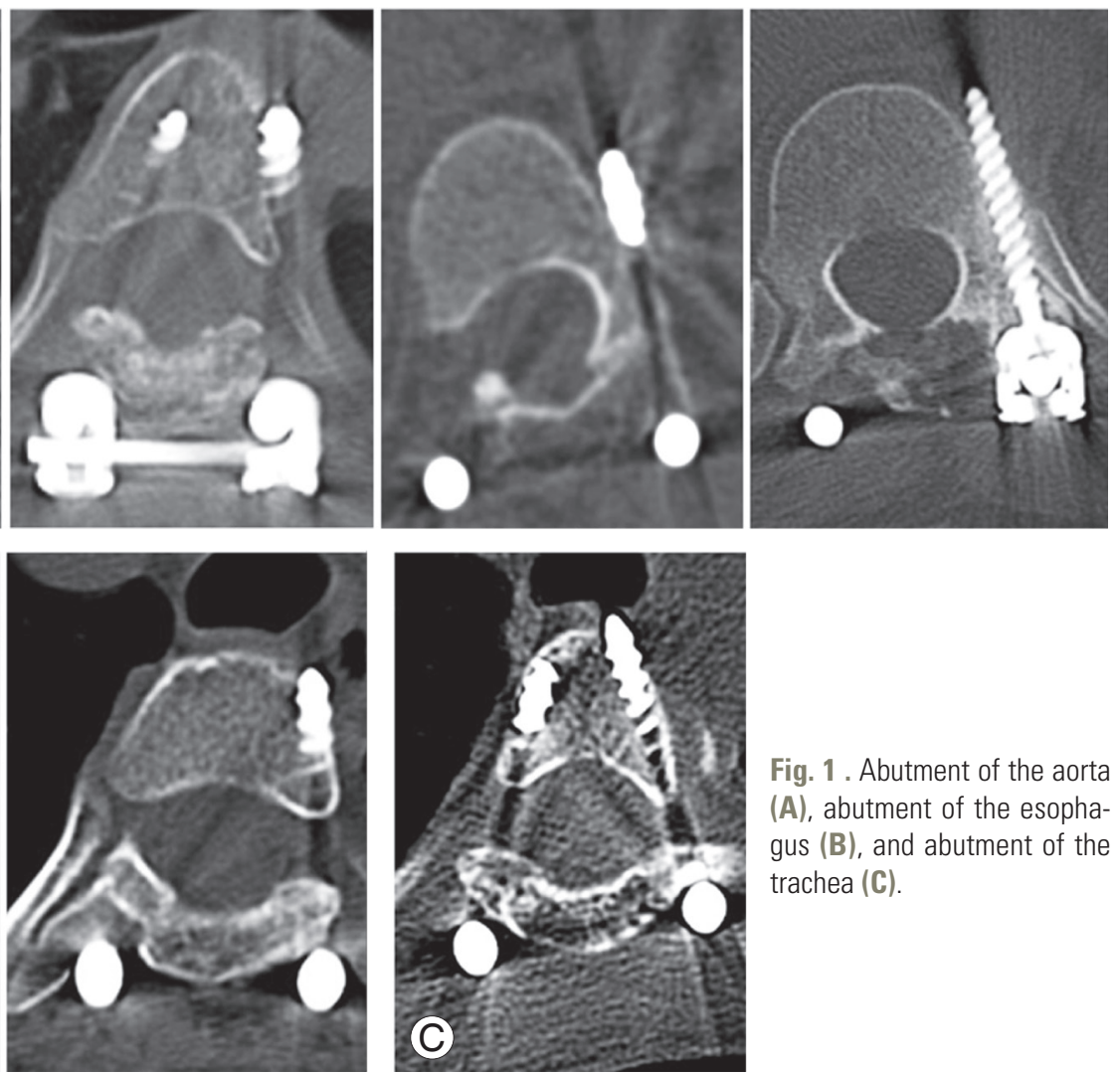

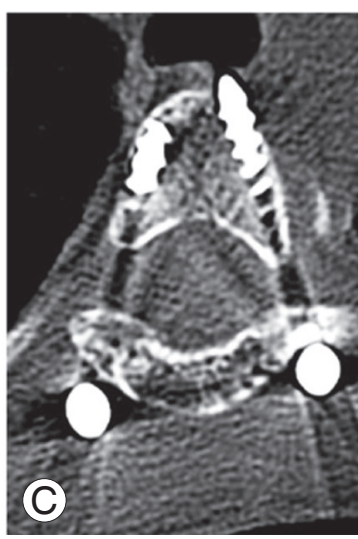

Fig. 1. Abutment of the aorta (A), abutment of the esophagus (B), and abutment of the trachea (C). 
safety of pedicle screw placement in patients with AIS [45]. This study reviewed a total of 2,020 pedicle screws from 140 patients with AIS using CT. The overall pedicle perforation rate was $18.3 \%(369 / 2,020$ screws), with $6.8 \%$ (138/2,020 screws), $2.8 \%$ (57/2020 screws), and $8.6 \%$ (174/2020 screws) of the perforations being grades 1, 2, and 3 , respectively. The overall anterior perforation rate was $2.0 \%(41 / 2,020)$. Majority perforations were due to lateral perforations occurring over the thoracic region, particularly over the right T3-T5 levels, which resulted from intentional application of extrapedicular screws at this region. These lateral perforations at the thoracic level (extrapedicular technique) were considered safe given that the screws were confined within the costovertebral junction. The exclusion of lateral perforations in the thoracic region (due to the extrapedicular screws) resulted in grade 1,2 , and 3 pedicle perforation rates of 5.0\% (101 screws), $1.3 \%$ (27 screws), and $0.2 \%$ (4 screws), respectively. Only two symptomatic left medial grade 2 perforations were found: one screw at T12 presented with postoperative iliac crest numbness, whereas another screw at L2 presented with radicular pain that subsided with conservative treatment. Moreover, four anterior perforations were abutting the aorta (due to $30-\mathrm{mm}$ screws at the left T4 and T5 and a 35-mm screw over the left T12 in two cases), two anterior perforations had caused esophageal abutment (due to a $25-$ and $30-\mathrm{mm}$ screw at $\mathrm{T} 2$ and $\mathrm{T} 3$, respectively), and one screw was abutting the trachea (due to a $30-\mathrm{mm}$ screw at T4) (Fig. 1). No spinal cord, aortic, esophageal, or lung injuries were caused by malpositioned screws, and no revision surgery was required for all of the cases. This study concluded that the overall critical pedicle perforation rate (defined as perforations $>2 \mathrm{~mm}$ ) and critical anterior perforation rate (defined as perforations $>4 \mathrm{~mm}$ ) were $1.5 \%(21 / 2,020)$ and $0.7 \%(13 / 2,020)$, respectively. Moreover, only $0.1 \%$ of screw perforations had led to radicular symptoms. This series showed that abutment of important structures, i.e., the esophagus, trachea, and aorta, can occur even with very short screws [45].

\section{Future research}

Based on the current literature review, sufficient published data are available on the anatomical morphology of the scoliotic spine and its relationship with important visceral structures [11,12,19-26]. Moreover, adequate published data documenting the perforation rate after scoliosis sur- gery are readily obtainable (Tables 1,2 ) [28-49]. Future studies should focus on standardizing perforation grading and definitions for both pedicle and anterior perforations. Studies regarding risk stratification for pedicle perforation, e.g., identification and location of dysplastic pedicles in a scoliotic curve wherein pedicle screw insertion would be challenging will be helpful for surgeons. This would also help lower the risk for critical perforations, which could lead to adverse clinical events. Perforation rate reduction can also be achieved through modification of the pedicle screw design, i.e., removing the medial thread of the screw, which has been shown to reduce the rate of medial perforations in a cadaveric model [63]. The use of robotics for scoliosis surgery as well as patient templatespecific drill guides for pedicle screw insertion are also being studied $[64,65]$.

\section{Conclusions}

Pedicle screws provide better biomechanical advantages, which translate into higher correction rates after scoliosis surgery. However, this technique has the risk for causing injuries to the nervous system as well as to the surrounding viscera, i.e., the aorta, azygos vein, and esophagus. Therefore, deformity surgeons should have sound knowledge on the morphometry of the deformed spine and its surrounding visceral structures to prevent catastrophic events. The use of navigation technology has shown to reduce perforation rates associated with screw placement.

\section{Conflict of Interest}

No potential conflict of interest relevant to this article was reported.

\section{References}

1. Boucher HH. A method of spinal fusion. J Bone Joint Surg Br 1959;41:248-59.

2. Harrington PR, Tullos HS. Reduction of severe spondylolisthesis in children. South Med J 1969;62:1-7.

3. Roy-Camille R, Saillant G, Mazel C. Internal fixation of the lumbar spine with pedicle screw plating. Clin Orthop Relat Res 1986;(203):7-17.

4. An HS, Singh K, Vaccaro AR, et al. Biomechanical evaluation of contemporary posterior spinal internal fixation configurations in an unstable burst-fracture 
calf spine model: special references of hook configurations and pedicle screws. Spine (Phila Pa 1976) 2004;29:257-62.

5. Kim YJ, Lenke LG, Cho SK, Bridwell KH, Sides B, Blanke K. Comparative analysis of pedicle screw versus hook instrumentation in posterior spinal fusion of adolescent idiopathic scoliosis. Spine (Phila Pa 1976) 2004;29:2040-8.

6. Dobbs MB, Lenke LG, Kim YJ, Kamath G, Peelle MW, Bridwell KH. Selective posterior thoracic fusions for adolescent idiopathic scoliosis: comparison of hooks versus pedicle screws. Spine (Phila Pa 1976) 2006;31:2400-4.

7. Kim YJ, Lenke LG, Kim J, et al. Comparative analysis of pedicle screw versus hybrid instrumentation in posterior spinal fusion of adolescent idiopathic scoliosis. Spine (Phila Pa 1976) 2006;31:291-8.

8. Barr SJ, Schuette AM, Emans JB. Lumbar pedicle screws versus hooks: results in double major curves in adolescent idiopathic scoliosis. Spine (Phila Pa 1976) 1997;22:1369-79.

9. Hamill CL, Lenke LG, Bridwell KH, Chapman MP, Blanke K, Baldus C. The use of pedicle screw fixation to improve correction in the lumbar spine of patients with idiopathic scoliosis. Is it warranted? Spine (Phila Pa 1976) 1996;21:1241-9.

10. Dobbs MB, Lenke LG, Kim YJ, Luhmann SJ, Bridwell $\mathrm{KH}$. Anterior/posterior spinal instrumentation versus posterior instrumentation alone for the treatment of adolescent idiopathic scoliotic curves more than 90 degrees. Spine (Phila Pa 1976) 2006;31:2386-91.

11. Jiang H, Qiu X, Wang W, et al. The position of the aorta changes with altered body position in single right thoracic adolescent idiopathic scoliosis: a magnetic resonance imaging study. Spine (Phila Pa 1976) 2012;37:E1054-61.

12. Jiang J, Qian BP, Qiu Y, Wang B, Yu Y, Zhu ZZ. The azygous vein is at potential risk of injury from malpositioning of left thoracic pedicle screw in thoracic adolescent idiopathic scoliosis patients. Spine (Phila Pa 1976) 2017;42:E920-5.

13. Sariyilmaz K, Ozkunt O, Sungur M, Dikici F, Domanic U. Esophageal perforation caused by a posterior pedicle screw: a case report. J Pediatr Orthop 2017;37:98-101.

14. Panjabi MM, Takata K, Goel V, et al. Thoracic human vertebrae: quantitative three-dimensional anatomy.
Spine (Phila Pa 1976) 1991;16:888-901.

15. Zindrick MR, Wiltse LL, Doornik A, et al. Analysis of the morphometric characteristics of the thoracic and lumbar pedicles. Spine (Phila Pa 1976) 1987;12:1606.

16. Vaccaro AR, Rizzolo SJ, Allardyce TJ, et al. Placement of pedicle screws in the thoracic spine. Part I: Morphometric analysis of the thoracic vertebrae. J Bone Joint Surg Am 1995;77:1193-9.

17. Tan SH, Teo EC, Chua HC. Quantitative threedimensional anatomy of cervical, thoracic and lumbar vertebrae of Chinese Singaporeans. Eur Spine J 2004;13:137-46.

18. Datir SP, Mitra SR. Morphometric study of the thoracic vertebral pedicle in an Indian population. Spine (Phila Pa 1976) 2004;29:1174-81.

19. Liljenqvist UR, Link TM, Halm HF. Morphometric analysis of thoracic and lumbar vertebrae in idiopathic scoliosis. Spine (Phila Pa 1976) 2000;25:124753.

20. Parent S, Labelle H, Skalli W, de Guise J. Thoracic pedicle morphometry in vertebrae from scoliotic spines. Spine (Phila Pa 1976) 2004;29:239-48.

21. Sarwahi V, Sugarman EP, Wollowick AL, Amaral TD, Lo Y, Thornhill B. Prevalence, Distribution, and Surgical Relevance of Abnormal Pedicles in Spines with Adolescent Idiopathic Scoliosis vs. No Deformity: A CT-Based Study. J Bone Joint Surg Am 2014;96:e92.

22. Czerwein J, Sarwahi V, Friend L, Sharan A, Amaral T, Thornhill B. A new CT based classification of pedicles in spinal deformity. Spine J 2007;7:115S-6S.

23. Watanabe K, Lenke LG, Matsumoto M, et al. A novel pedicle channel classification describing osseous anatomy: how many thoracic scoliotic pedicles have cancellous channels? Spine (Phila Pa 1976) 2010;35:1836-42.

24. Sarlak AY, Buluc L, Sarisoy HT, Memisoglu K, Tosun B. Placement of pedicle screws in thoracic idiopathic scoliosis: a magnetic resonance imaging analysis of screw placement relative to structures at risk. Eur Spine J 2008;17:657-62.

25. Liu J, Shen J, Zhang J, et al. The position of the aorta relative to the spine for pedicle screw placement in the correction of idiopathic scoliosis. J Spinal Disord Tech 2012;25:E103-7.

26. Takeshita K, Maruyama T, Sugita S, et al. Is a right pedicle screw always away from the aorta in scolio- 
sis? Spine (Phila Pa 1976) 2011;36:E1519-24.

27. Takeshita K, Maruyama T, Chikuda H, et al. Diameter, length, and direction of pedicle screws for scoliotic spine: analysis by multiplanar reconstruction of computed tomography. Spine (Phila Pa 1976) 2009;34:798-803.

28. Suk SI, Kim WJ, Lee SM, Kim JH, Chung ER. Thoracic pedicle screw fixation in spinal deformities: are they really safe? Spine (Phila Pa 1976) 2001;26:204957.

29. Kim YJ, Lenke LG, Bridwell KH, Cho YS, Riew KD. Free hand pedicle screw placement in the thoracic spine: is it safe? Spine (Phila Pa 1976) 2004;29:33342.

30. Kim YJ, Lenke LG, Cheh G, Riew KD. Evaluation of pedicle screw placement in the deformed spine using intraoperative plain radiographs: a comparison with computerized tomography. Spine (Phila Pa 1976) 2005;30:2084-8.

31. Smorgick Y, Millgram MA, Anekstein Y, Floman Y, Mirovsky Y. Accuracy and safety of thoracic pedicle screw placement in spinal deformities. J Spinal Disord Tech 2005;18:522-6.

32. Lehman RA Jr, Lenke LG, Keeler KA, Kim YJ, Cheh G. Computed tomography evaluation of pedicle screws placed in the pediatric deformed spine over an 8-year period. Spine (Phila Pa 1976) 2007;32:2679-84.

33. Di Silvestre M, Parisini P, Lolli F, Bakaloudis G. Complications of thoracic pedicle screws in scoliosis treatment. Spine (Phila Pa 1976) 2007;32:1655-61.

34. Rajasekaran S, Vidyadhara S, Ramesh P, Shetty AP. Randomized clinical study to compare the accuracy of navigated and non-navigated thoracic pedicle screws in deformity correction surgeries. Spine (Phila Pa 1976) 2007;32:E56-64.

35. Li G, Lv G, Passias P, et al. Complications associated with thoracic pedicle screws in spinal deformity. Eur Spine J 2010;19:1576-84.

36. Liljenqvist UR, Halm HF, Link TM. Pedicle screw instrumentation of the thoracic spine in idiopathic scoliosis. Spine (Phila Pa 1976) 1997;22:2239-45.

37. Halm H, Niemeyer T, Link T, Liljenqvist U. Segmental pedicle screw instrumentation in idiopathic thoracolumbar and lumbar scoliosis. Eur Spine J 2000;9:191-7.

38. Suk SI, Lee SM, Chung ER, Kim JH, Kim SS. Selective thoracic fusion with segmental pedicle screw fix- ation in the treatment of thoracic idiopathic scoliosis: more than 5-year follow-up. Spine (Phila Pa 1976) 2005;30:1602-9.

39. Kuklo TR, Lenke LG, O’Brien MF, Lehman RA Jr, Polly DW Jr, Schroeder TM. Accuracy and efficacy of thoracic pedicle screws in curves more than 90 degrees. Spine (Phila Pa 1976) 2005;30:222-6.

40. Yingsakmongkol W, Hangsaphuk N, Lerdlam S. The accuracy of pedicle screw placement in thoracic spine using the Funnel technique in idiopathic scoliosis. J Med Assoc Thai 2007;90:96-105.

41. Sakai Y, Matsuyama Y, Nakamura H, et al. Segmental pedicle screwing for idiopathic scoliosis using computer-assisted surgery. J Spinal Disord Tech 2008;21:181-6.

42. Sarlak AY, Tosun B, Atmaca H, Sarisoy HT, Buluc L. Evaluation of thoracic pedicle screw placement in adolescent idiopathic scoliosis. Eur Spine J 2009;18:1892-7.

43. Samdani AF, Ranade A, Sciubba DM, et al. Accuracy of free-hand placement of thoracic pedicle screws in adolescent idiopathic scoliosis: how much of a difference does surgeon experience make? Eur Spine J 2010;19:91-5.

44. Liu Z, Jin M, Qiu Y, Yan H, Han X, Zhu Z. The superiority of intraoperative $\mathrm{O}$-arm navigation-assisted surgery in instrumenting extremely small thoracic pedicles of adolescent idiopathic scoliosis: a casecontrol study. Medicine (Baltimore) 2016;95:e3581.

45. Kwan MK, Chiu CK, Gani SM, Wei CC. Accuracy and safety of pedicle screw placement in adolescent idiopathic scoliosis patients: a review of 2020 screws using computed tomography assessment. Spine (Phila Pa 1976) 2017;42:326-35.

46. Merloz P, Huberson C, Tonetti JM, Vouaillat HM. Computer-assisted pedicle screw insertion. Tech Orthop 2003;18:149-59.

47. Cui G, Wang Y, Kao TH, et al. Application of intraoperative computed tomography with or without navigation system in surgical correction of spinal deformity: a preliminary result of 59 consecutive human cases. Spine (Phila Pa 1976) 2012;37:891-900.

48. Takahashi J, Hirabayashi H, Hashidate H, Ogihara N, Kato H. Accuracy of multilevel registration in imageguided pedicle screw insertion for adolescent idiopathic scoliosis. Spine (Phila Pa 1976) 2010;35:34752. 
49. Zhang W, Takigawa T, Wu Y, Sugimoto Y, Tanaka M, Ozaki T. Accuracy of pedicle screw insertion in posterior scoliosis surgery: a comparison between intraoperative navigation and preoperative navigation techniques. Eur Spine J 2017;26:1756-64.

50. Hicks JM, Singla A, Shen FH, Arlet V. Complications of pedicle screw fixation in scoliosis surgery: a systematic review. Spine (Phila Pa 1976) 2010;35:E46570.

51. Sarwahi V, Wendolowski SF, Gecelter RC, et al. Are we underestimating the significance of pedicle screw misplacement? Spine (Phila Pa 1976) 2016;41:E54855.

52. Hamilton DK, Smith JS, Sansur CA, et al. Rates of new neurological deficit associated with spine surgery based on 108,419 procedures: a report of the scoliosis research society morbidity and mortality committee. Spine (Phila Pa 1976) 2011;36:1218-28.

53. Samdani AF, Belin EJ, Bennett JT, et al. Unplanned return to the operating room in patients with adolescent idiopathic scoliosis: are we doing better with pedicle screws? Spine (Phila Pa 1976) 2013;38:18427.

54. Mac-Thiong JM, Parent S, Poitras B, Joncas J, Hubert L. Neurological outcome and management of pedicle screws misplaced totally within the spinal canal. Spine (Phila Pa 1976) 2013;38:229-37.

55. Dede O, Ward WT, Bosch P, Bowles AJ, Roach JW. Using the freehand pedicle screw placement technique in adolescent idiopathic scoliosis surgery: what is the incidence of neurological symptoms secondary to misplaced screws? Spine (Phila Pa 1976) 2014;39:286-90.

56. Tian W, Zeng C, An Y, Wang C, Liu Y, Li J. Accuracy and postoperative assessment of pedicle screw placement during scoliosis surgery with computerassisted navigation: a meta-analysis. Int J Med Robot 2017;13:e1732.
57. Sucato DJ, Kassab F, Dempsey M. Analysis of screw placement relative to the aorta and spinal canal following anterior instrumentation for thoracic idiopathic scoliosis. Spine (Phila Pa 1976) 2004;29:554-9.

58. Watanabe K, Yamazaki A, Hirano T, et al. Descending aortic injury by a thoracic pedicle screw during posterior reconstructive surgery: a case report. Spine (Phila Pa 1976) 2010;35:E1064-8.

59. Kakkos SK, Shepard AD. Delayed presentation of aortic injury by pedicle screws: report of two cases and review of the literature. J Vasc Surg 2008;47:107482.

60. Minor ME, Morrissey NJ, Peress R, et al. Endovascular treatment of an iatrogenic thoracic aortic injury after spinal instrumentation: case report. J Vasc Surg 2004;39:893-6.

61. Iyer MH, Engoren M, Martin MW. Echo rounds: Transesophageal echocardiography: identification and management of a misplaced pedicle screw in the descending thoracic aorta after posterior spinal fusion. Anesth Analg 2013;116:303-6.

62. Wagner MR, Flores JB, Sanpera I, Herrera-Soto J. Aortic abutment after direct vertebral rotation: plowing of pedicle screws. Spine (Phila Pa 1976) 2011;36:243-7.

63. Kwan MK, Chan CY, Saw LB, Rukmanikanthan S, Lenke LG. The safety and strength of a novel medial, partial nonthreaded pedicle screw: a cadaveric and biomechanical investigation. Clin Spine Surg 2017;30:E297-E304.

64. Lu S, Zhang YZ, Wang Z, et al. Accuracy and efficacy of thoracic pedicle screws in scoliosis with patient-specific drill template. Med Biol Eng Comput 2012;50:751-8.

65. Macke JJ, Woo R, Varich L. Accuracy of robot-assisted pedicle screw placement for adolescent idiopathic scoliosis in the pediatric population. J Robot Surg 2016;10:145-50. 